\title{
O canto de Clara: possibilidades de ensino- -aprendizagem da história afro-brasileira
}

The singing of Clara: teaching and learning possibilities of African-Brazilian history

Luciano Magela Roza*

\section{Resumo}

$\mathrm{O}$ artigo tem como objetivo a reflexão sobre possibilidades de utilização da obra musical da intérprete Clara Nunes como recurso didático para o ensino-aprendizagem de alguns aspectos da história afro-brasileira. Tal reflexão parte de pressupostos relacionados, de um lado, ao ensino de história e, de outro, à apropriação da música como linguagem para o ensino-aprendizagem em contexto escolar, assim como recurso substantivo para a compreensão do mundo social. Considerando-se os elementos musicais e extramusicais presentes na produção cultural de Clara Nunes, buscaremos discutir como a referida produção pode contribuir para a problematização de questões postas na efetivação da Lei 10.639/2003.

Palavras-chave: Clara Nunes; ensino de história; história afro-brasileira.

\section{Abstract}

This article aims to reflect on possibilities of use of the musical work of the interpreter Clara Nunes as a teaching resource for teaching and learning some aspects of African-Brazilian history. This reflection is based on assumptions related to the teaching of history and on the appropriation of music as a language for teaching and learning in schools, as well as substantive resource for understanding the social world. Considering the musical and extra-musical elements present in the cultural production of Clara Nunes, we discuss how such production can contribute to problematic issues put into effect in the Law 10.639/2003.

Keywords: Clara Nunes; History teaching; African-Brazilian history.

Nas últimas décadas, a formação dos licenciados em História vem sendo impactada por um conjunto de proposições e diretrizes gestado no interior de diferentes campos de referência, tais como a historiografia, a teoria da história,

\footnotetext{
* Doutor em Educação pela Universidade Federal de Minas Gerais (UFMG). Professor do Departamento de História da Universidade Federal dos Vales do Jequitinhonha e Mucuri (UFVJM). Diamantina, MG, Brasil. lucianoroza@gmail.com
} 
as pesquisas sobre ensino de história e a teoria curricular, entre outros, assim como por interferências do mundo social, políticas curriculares, usos do passado pelos meios de comunicação de massa, movimentos sociais e políticos etc.

Nesse contexto, demandas formativas diversas, tais como o uso de tecnologias em ambiência escolar, a apropriação com finalidades didáticas de diferentes linguagens em circulação no mundo social, a incorporação da dimensão patrimonial ao ensino e a emergência da temática das diversidades como preocupação educativa, têm ganhado importância na formação inicial e continuada e na atuação em contexto escolar dos licenciados. Considerando o contexto apontado, este artigo propõe uma reflexão sobre a utilização da música como parte do processo de produção do conhecimento histórico na escola no tratamento da História e cultura afro-brasileira e africana no currículo escolar.

A obrigatoriedade da temática africana e afro-brasileira como conteúdo curricular obrigatório da Educação Básica, posta a partir da Lei 10.639/03 e reafirmada nas Diretrizes Curriculares Nacionais para a Educação das Relações Étnico-raciais e para o Ensino de História e Cultura Africana e Afro-brasileira, produziu simultaneamente, por um lado, novas questões, tensões e inquietações em diversos espaços sociais, e, por outro, a necessidade de elaboração de novas e diversas abordagens, metodologias e ações pedagógicas para o tratamento dos temas postos a partir daí. Além disso, é importante ressaltar que a referida legislação busca, nas disputas constitutivas do campo do currículo escolar, redimensionar o lugar reservado aos africanos e afro-brasileiros na memória coletiva do país e na narrativa nacional.

Buscando contribuir para esse debate, a centralidade deste artigo reside na discussão sobre as possibilidades de apropriação das representações ${ }^{2}$ relacionadas à identidade e à cultura afro-brasileira, produzidas e em circulação na obra artística da cantora Clara Nunes como recurso didático para problematização de aspectos relacionados ao ensino-aprendizagem da história afro-brasileira.

A opção pela obra da referida intérprete como objeto de análise e de reflexão didática deve-se a dois aspectos: 1) sua importância no mercado fonográfico brasileiro entre as décadas de 1960 e 1980, como a primeira mulher a vender mais de cem mil cópias de disco, portanto, uma produção de grande penetração pública; e 2) pela quantidade de representações relativas à cultura 
e identidade afro-brasileiras que circulavam no repertório selecionado pela e para a artista, e pela imagem veiculada por ela.

\section{Clara e a construção do afro}

A música popular em circulação midiática é resultado da ação coletiva de uma série de agentes sociais que trabalham na indústria fonográfica. Compositores, intérpretes, arranjadores, músicos, fotógrafos, gerentes de marketing, diretores artísticos e divulgadores de gravadoras, entre outros, são exemplos de tais agentes. Contudo, a despeito do poder de intervenção artística da indústria da música, historicamente e em ampla circulação social na atualidade, há uma visão de senso comum que considera a música popular como produto decorrente da iniciativa do artista que a interpreta e/ou a compõe.

A produção artística de Clara Nunes consolidou-se na memória coletiva brasileira atrelada a elementos da identidade negra, especialmente aos relativos à religiosidade de matriz africana.

A proposta de observarmos em perspectiva histórica a obra de Clara deve-se à necessidade de compreensão da natureza polissêmica da música popular produzida na contemporaneidade, entendida simultaneamente como produto de mercado e produto cultural. Assim, o que buscamos realizar no trabalho pedagógico com a linguagem musical é a tentativa de superar o senso comum de entendimento da música, anteriormente apontado, ao colocarmos em evidência a possibilidade de compreensão de alguns aspectos do processo de "fabricação" da música como artefato cultural e mercadológico.

Diante disso, objetivando uma visão mais abrangente acerca da forma como os elementos afro-brasileiros foram sendo construídos na trajetória artística em foco, dois recursos tornam-se fundamentais. O primeiro são as chamadas informações extramusicais, ${ }^{3}$ observadas nas capas e contracapas dos discos de Clara Nunes, nos depoimentos de sujeitos envolvidos na construção da imagem da artista e na seleção de composições presente em sua obra. O segundo são os elementos poético-musicais, ${ }^{4}$ ou seja, as letras das músicas e as próprias canções gravadas pela intérprete.

O início da carreira fonográfica de Clara Nunes foi marcado pela criação de uma imagem da intérprete como cantora romântica. Indícios podem ser observados nas canções que compõem os LPs A voz adorável de Clara Nunes, 
lançado em 1966, Você passa e eu acho graça, de 1968, e A beleza que canta, que data de 1969. Nesses LPs, o repertório da cantora era formado, majoritariamente, por um conjunto de composições que mesclava boleros, sambas-canção e canções de novos compositores na nascente MPB com temáticas românticas.

Além das próprias canções, outra evidência do objetivo de fazer da cantora um ícone romântico se observa na contracapa do primeiro álbum da Clara, onde consta este texto: “A voz adorável de Clara Nunes aqui está, com aquele seu quê envolvente, que a fará uma das maiores cantoras românticas do Brasil”. ${ }^{5}$

As capas dos discos citados são fontes históricas e recursos didáticos substanciais para compreensão da produção da cantora, e podem contribuir para a discussão em tela. A respeito das capas de álbuns, Hermeto (2012, p.75) afirma que

As capas dos álbuns, por exemplo, são fontes importantes para se pensar na canção popular a um só tempo como produto cultural e produto de mercado. Em geral, esses documentos traduzem o conceito musical e comercial do disco, permitindo identificar o público-alvo preferencial e as relações dos artistas no campo da canção popular. Além disso, são de muito fácil acesso, tanto por se encontrarem dispersas no cotidiano dos brasileiros, quanto, atualmente, por estarem disponíveis na internet.

A análise das capas dos LPs de Clara Nunes produzidos no período de 1966 a 1969 possibilita observarmos o conceito musical e comercial dos discos, o que reafirma a tentativa de fazer da cantora uma representante da música romântica.

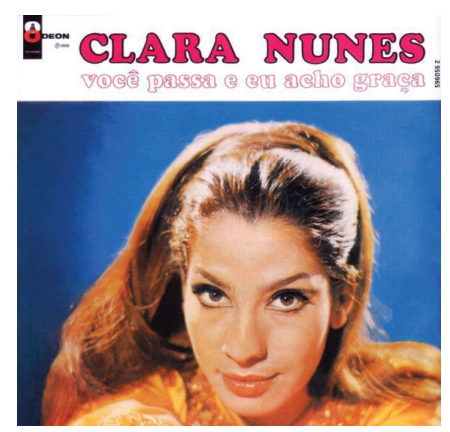

Figura 1 - Capa do LP Você passa e eu acho graça

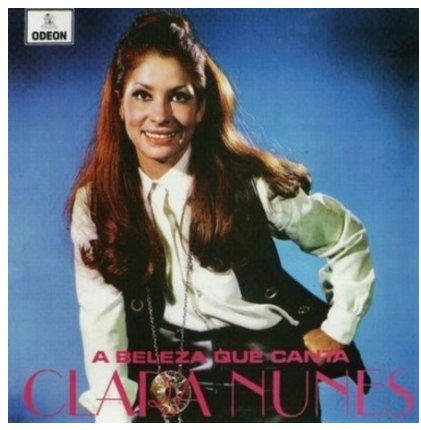

Figura 2 - Capa do LP A beleza que encanta 
Ademais, analisando as capas dos long plays (LPs), não é possível observar nenhum traço de figuração relacionada a elementos afro-brasileiros. ${ }^{6}$ Bakke (2007), buscando verificar na obra de Clara Nunes a presença da influência do candomblé e da umbanda na música popular brasileira, ao analisar capas dos discos da intérprete no mesmo contexto, ${ }^{7}$ conclui que "a cantora aparece com a pele bem alva, contrastando com o cabelo escuro e liso, penteado à moda das cantoras de rádio das décadas de 1940 e 1950" (Bakke, 2007, p.94).

Vagner Fernandes, biógrafo da cantora, afirma que além de Clara participar em diversos momentos de religiões de matriz africana, "havia algum tempo, ela já martelava a ideia de enveredar pelo caminho do resgate da sonoridade afro-brasileira" (Fernandes, 2007, p.114). A emergência de elementos afro-brasileiros em sua performance, tanto em relação aos aspectos visuais como aos poético-musicais, ocorrerá somente a partir do disco Clara Nunes, de 1971, sob direção artística do radialista Adelzon Alves.

O radialista foi chamado pelos executivos da gravadora EMI-Odeon na tentativa de dar uma nova formatação à carreira da jovem cantora. Em depoimento, Adelzon (in Fernandes, 2007, p.115) declara que:

A Clara era determinada, queria fazer uma carreira brilhante como cantora, mas faltava-lhe orientação, alguém para definir um rumo ... Quando eu fui chamado, disse que só aceitava dirigi-la se fosse feito um trabalho no qual eu acreditasse. Escrevi um texto, que está na capa do primeiro disco que produzi, dizendo que, depois da morte de Carmen Miranda, nenhuma outra artista brasileira havia assumido o afro, tanto do ponto de vista sonoro quanto do visual.

A partir desse momento, o que se observa nas capas e contracapas dos discos, assim como em parte do repertório musical selecionado pela artista e para ela, é o desmonte de uma cantora que girava em torno de um repertório romântico e a construção de uma imagem de uma artista associada a elementos afro-brasileiros e ao resgate da cultura popular brasileira. Segundo Fernandes (2007, p.137):

Isso agradaria tanto às classes mais pobres, já que as canções assinadas por compositores falavam-lhes ao coração, quanto às elites e intelectuais, que viam em Clara mais uma aliada com voz ativa e tremendo potencial de resistência à enlatada música norte-americana que se disseminava nas rádios bra- 
sileiras. Clara agradava a pobres e ricos. A articulada e estratégica mudança de estilo não lhe poderia render melhor marketing. Com Adelzon, ela agiu rápido. Foi inteligente. Preencheu a lacuna que faltava, dando categoria profissional a um primitivo gênero, belo, rico e variado. A Clara Nunes que ficaria eternizada no imaginário popular, com seu canto arrebatador, suas vestimentas e expressão corporal que remetiam aos cultos afro-brasileiros, foi criada a partir de uma cuidadosa pesquisa.

Essa estratégia de construção de uma nova imagem para a cantora pode se verificar no texto de Adelzon Alves impresso na contracapa do LP Clara Nunes (1971). O produtor apresenta Clara assim:

Meu cumpade (sic), o negócio é o seguinte: a partir da música Misticismo da África no Brasil, que a moçada vem escutando todo dia, é só ligar a 'caixa de conversa'; Clara Nunes toma uma posição bem definida dentro das raízes da cultura popular brasileira. Nesse LP, o sabiá num 'brinca em serviço'. Dá seu recado com músicas, sons e os refrões (sic) do candomblé e da 'Puxada da rede do xaréu', estes últimos ligados à vida econômica, religiosa e artística da Bahia (folclore), que fazem parte da nova imagem audiovisual que a cantora vem mostrando ao público nos seus shows, apresentações de televisão etc. Essa imagem é o aproveitamento das formas, cores, sons, ritmos etc. e tal da cultura popular brasileira. ${ }^{8}$

É interessante percebermos que a construção do afro em Clara Nunes continuou como elemento central em sua performance mesmo depois da ruptura com Adelzon, ocorrida em 1974. Paulo César Pinheiro, marido e produtor da cantora entre 1974 e 1983, relata que

Quando ela resolveu abraçar as músicas de teor afro-brasileiro, em uma época em que não se cantavam canções sobre orixás, procurou a Mercedes Batista, professora de dança afro. Queria mostrar dançando o que estava cantando, o significado das letras, dos orixás. Quando ela pisava no palco e dançava, não era uma coisa à toa, era algo preconcebido. (Pinheiro apud Fernandes, 2007, p.182-183)

A contracapa e a capa dos álbuns reproduzidos nas Figuras 3 e 4 indicam a presença de representações da africanidade na obra da intérprete durante a década de 1980. 


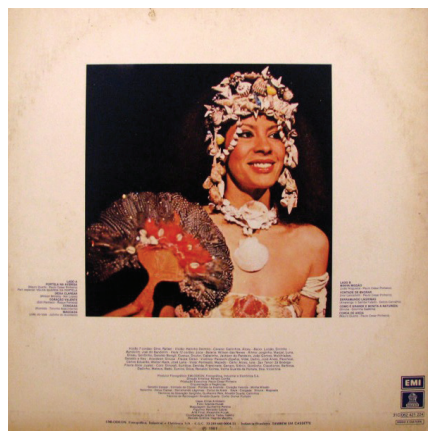

Figura 3 - Contracapa do LP Clara (1981)

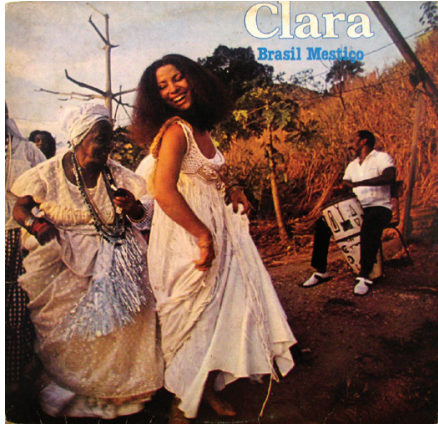

Figura 4 - Capa do LP Brasil Mestiço

Nas reproduções da contracapa (Figura 3) e da capa (Figura 4), a imagem de Clara Nunes já estava consolidada como referencial à cultura afro-brasileira. As duas fotografias aí presentes, ambas produzidas pelo fotógrafo Wilton Montenegro, trazem a intérprete paramentada com adornos pertencentes a orixás femininos do candomblé (coroa de concha estilizado, colar de conchas, leque de penas de pavão, braceletes etc.) no terreiro no Morro da Serrinha, em Madureira (Rio de Janeiro), com a amiga e conselheira espiritual Vovó Maria Joana, ambas vestidas com roupas que remetem a tradições religiosas afro-brasileiras. Além dos conselhos espirituais, Vovó Maria Joana tem sua imagem associada à preservação do jongo no Morro da Serrinha.

A opção feita neste trabalho de dar evidência à construção dos aspectos de africanidade na obra de Clara Nunes, com parte da produção, circulação e consumo da música como artefato cultural e mercadoria, tal como podemos verificar nos depoimentos de Adelzon e Paulo César, assim como a capa e a contracapa reproduzidas aqui, não têm como objetivo diminuir a relevância da produção da artista no que tange à valorização cultural e identitária negra. Ao contrário, tal preferência decorre da necessidade de problematizar a construção de identidades no interior da cultura de massa, construção essa permeada pela interferência de diversos sujeitos sociais e de interesses e disputas várias, o que rompe com uma ideia ingênua acerca do modo de produção na cultura nas sociedades contemporâneas, especialmente quando essa produção é mediada pelo mercado. 


\section{VALORIZAÇÃO DA HETEROGENEIDADE CULTURAL E IDENTITÁRIA AFRO-BRASILEIRA}

A visibilidade positiva da multiplicidade de aspectos relativos à cultura e à identidade negras no Brasil verificada na obra de Clara Nunes torna-se recurso frutífero para a problematização de elementos significativos para o ensino-aprendizagem da história afro-brasileira, especialmente no que tange à criação e circulação de representações. Nesse sentido, compreendemos que a performance da artista, ao evidenciar positivamente variedades culturais e identitárias afro-brasileiras, criou uma espécie de política de representação.

A noção de "política de representação" trata de uma ação consciente e organizada com finalidade de criar representações que busquem colocar em circulação social e pública representações outrora estigmatizadas e/ou invisibilizadas, tal como ocorreu com a categoria black (negro) na política cultural e identitária negra inglesa, a partir dos anos 1960. De acordo com Hall (1997a; 1997b), o termo black, outrora considerado pejorativo, passa a ser apropriado de forma positiva, como uma construção política e cultural pelos movimentos antirracistas no Reino Unido, a partir do contexto apontado. Assim, o termo, anteriormente compreendido como referência negativa da representação da experiência negra, passa a ser trabalhado, cultural e politicamente, sob novo significado, positivo e incorporado como índice de resistência no campo simbólico das lutas de representação.

Por meio da chamada política de representação ocorre uma ação político-cultural de construção discursiva do mundo social, que, por um processo de ressignificação de representações e imaginários, busca intervir na produção e reprodução de leituras estereotipadas de grupos particulares. Nesse processo, as representações são entendidas como momentos constitutivos no campo do simbólico, que possuem a capacidade de informar e influenciar condutas e práticas nas relações sociais, e não como expressões de realidades e relações constituídas antecipadamente. ${ }^{9}$

Ao deslocarmos o foco para a obra de Clara Nunes, verifica-se a recorrência de temas alusivos ao universo histórico e cultural afro-brasileiro, assim como o trânsito por gêneros musicais relacionados a ele. Tais temas e gêneros são interpretados buscando criar uma mudança de perspectiva acerca de seus sentidos, alterando-se de aspectos negativos para uma perspectiva positivada, 
o que faz a música popular ser entendida como território do desenvolvimento de lutas de representação. ${ }^{10}$

É interessante observarmos que, apesar de Clara Nunes ter composto apenas uma canção, a música À flor da pele, em parceria com Maurício Tapajós e Paulo César Pinheiro, a notoriedade atribuída a ela como figura representativa de valores identificados como afro-brasileiros ocorre, no que se refere às composições gravadas pela artista, à sua capacidade de interpretar o cancioneiro de diversos compositores. Tal capacidade interpretativa possibilitou, por parte do público, uma identificação direta entre canção e intérprete, gerando uma sensação de senso comum que considerava as canções interpretadas/cantadas por Clara como composições da própria cantora. Essa compreensão de senso comum evidencia o lugar do performer na cadeia produtiva da música popular na contemporaneidade e a produção de significados públicos e coletivos acerca do suposto protagonismo desses sujeitos, como alerta Hermeto (2012, p.52):

Atuação dos performers - arranjadores, instrumentistas e cantores - determina, em grande medida, o formato final da canção. Especialmente no caso da música popular, na qual a sua liberdade com relação à composição original e à notação musical clássica (nem sempre registrada, aliás) é muito grande ... Muitas das vezes, os performers imprimem sua marca na canção de tal forma que passam a ser tratados, eles próprios, como cancionistas - muitos deles nunca tendo se dedicado ao ofício de compor. Especialmente os cantores, cuja atuação é mais notada pelos ouvintes leigos em música, inclusive porque é em torno de sua figura que a indústria fonográfica se engendra, em grande medida.

A ação interpretativa do performer, especialmente dos cantores, produz um novo sentido para a composição original, conforme afirma Paranhos (2004, p.25):

interpretar implica também compor. Inevitavelmente, quando alguém canta e/ou apresenta uma música sob essa ou aquela roupagem instrumental, atua igualmente, num determinado sentido, como compositor. O agente opera, em maior ou menor medida, na perspectiva de decompor e/ou recompor uma composição.

Assim, por meio da força interpretativa engendrada pela cantora e de um repertório constituído por compositores diversos, identificamos que a 
valorização da pluralidade de gêneros musicais relacionados à cultura comumente identificada como negra no Brasil circula em uma perspectiva positiva na obra de Clara.

O universo sonoro em circulação no repertório de Clara relacionado à tradição afro-brasileira gira em torno de sambas-canção (Tudo é ilusão, de Eden Silva, Tufy Lauar e Anibal da Silva; Alvorecer, de autoria de Yvonne Lara e Delcio Carvalho), partidos-altos (Peixe com coco, de Alberto Lonato, Josias e Maceió do Cavaco, e Partido Clementina de Jesus, de autoria de Candeia), afoxés (Afoxé para Logun, de Nei Lopes, e Ijexá, do compositor Edil Pacheco), sambas-enredo (Seca do Nordeste, samba-enredo da Escola de Samba Tupi de Brás de Pina, e o samba-enredo da Portela, Macunaíma, herói da nossa gente, de autoria de Norival Reis e Davi Antônio Correia), congadas (Congada, de Romildo e Toninho Nascimento), pontos de umbanda e candomblé estilizados $^{11}$ (Coroa de Areia, dos compositores Mauro Duarte e Paulo César Pinheiro; Sindorerê, de Candeia, Senhora Das Candeias e Conto de Areia, da dupla Romildo e Toninho), capoeiras estilizadas (Jogo de Angola, da parceria Paulo César Pinheiro e Mauro Duarte, e Fuzuê, da dupla Romildo e Toninho) e jongos (Candongueiro, de Nei Lopes e Wilson Moreira).

A seleção de aspectos da cultura negra na obra de Clara Nunes parece-nos interessante no sentido de identificarmos uma espécie de política de representação ao colocar como central a valorização de ritmos, paramentos e temas relacionados à identidade negra. Nesse sentido, uma proposta didática interessante é propor o diálogo ou contraposição das representações promovidas pelo repertório da artista com outras representações sobre os afro-brasileiros em circulação em outros espaços midiáticos e na memória social.

A proposição da atividade de pesquisa escolar sobre os gêneros musicais, portadores de elementos afro-brasileiros ou não, que circulam na seleção de canções gravadas pela artista é outra atividade pedagógica direcionada para ampliação da fruição estética dos estudantes, assim como o alargamento em relação à diversidade rítmica e musical que compõe o patrimônio cultural entre nós. A imersão no universo sonoro em circulação no repertório da artista relativo às tradições musicais afro-brasileiras torna-se um imperativo interessante para a elaboração de práticas pedagógicas que considerem a fruição estética e o amplo terreno das sensibilidades sonoras, motoras, auditivas etc. como 
pontos fulcrais para o ensino-aprendizagem da história e, em especial, das histórias afro-brasileira, africanas e indígenas.

No contexto político e cultural brasileiro das décadas de 1970 e 1980, a perspectiva de retrabalhar a África e a ancestralidade a ela relacionada por meio da diversidade de ritmos e temas é outra faceta da produção artística em análise a ser observada como potencialidade para o trabalho pedagógico relativo à história afro-brasileira.

A ideia de "retrabalhar a África" implica trabalho de ressignificação e apropriação criativa por parte dos negros em diáspora, que buscam a construção de um pertencimento identitário nesse contexto permeado por práticas de hibridismo, localizadas em uma conjuntura assimétrica de relações de poder, compostas por referenciais culturais hegemônicos europeus. De acordo com Hall (2006, p.40),

retrabalhar a África ... tem sido o elemento mais poderoso e subversivo de nossa política cultural do século XX. E sua capacidade de estorvar o "acordo" nacionalista pós-independência ainda não terminou. Porém, isso não se deve principalmente ao fato de estarmos ligados ao nosso passado e herança africanos por uma cadeia inquebrantável, ao longo da qual uma cultura africana singular fluiu imutável por gerações, mas pela forma como nos propusemos a produzir de novo a "África", dentro da narrativa caribenha.

Nesse sentido, interessa-nos discutir a forma como a África é representada na obra de Clara, sendo essa perspectiva significativa para propostas pedagógicas que coloquem em sua centralidade a análise das representações sobre os africanos e seus descendentes na diáspora em diferentes temporalidades em circulação em artefatos culturais, tais como canções, filmes, minisséries, quadrinhos etc., uma vez que tais artefatos colocam em trânsito formas de conhecimento histórico e leituras sobre o passado, sem a preocupação do rigor cientifico e produzidas por agentes sociais fora da ambiência acadêmica. ${ }^{12}$

Além disso, o diálogo e/ou a contraposição das representações da africanidade na obra de Clara Nunes com a produção de outros compositores e/ou intérpretes assumidamente relacionados com a temática negra no Brasil é outro percurso didático interessante para compreendermos as diversas formas pelas quais essas representações foram sendo sedimentadas na canção popular entre nós. Assim, a produção fonográfica de artistas como Jorge Benjor, 
Wilson Simonal, blocos afro-baianos como o Olodum e o Ilê Aiyê e grupos de hip hop, entre outros, pode ser acionada buscando-se potencializar a compreensão da forma como a ideia de africanidade, cultura afro etc. é cambiante e historicamente contingente.

Ainda sobre o "retrabalhar a África”, os aspectos referentes às religiões de matriz africana presentes nas obras de Clara Nunes são outro percurso frutífero para o estudo da história afro-brasileira e africana. Nesse sentido, a obra da artista pode nos auxiliar nas discussões em contexto escolar sobre o modo como aspectos de diversas manifestações religiosas associadas às ancestralidades africanas são apropriados, ressignificados e valorizados pela música popular. Chamamos a atenção para as ideias de apropriação e de ressignificação como elementos chave no debate proposto por considerarmos que as religiões de matriz africana são expressões das formas como os africanos e descendentes reconstruíram identidades e práticas culturais em condições adversas, e não como uma continuidade inquebrável de traços culturais e ancestrais de tradições religiosas e societárias iniciadas em tempos imemoriais. O propósito é colocar luz no protagonismo de sujeitos que usaram da reinvenção identitária como forma de resistência.

As letras de algumas canções interpretadas por Clara trazem alguns indícios das representações sobre a ancestralidade africana. Em canções como Guerreira, composição de Paulo César Pinheiro e João Nogueira, Mãe África (Sivuca e Paulo César Pinheiro), Congada e Brasil mestiço, santuário da fé (Mauro Duarte e Paulo César Pinheiro), Nanae, Nana Naiana do compositor Sidney da Conceição, Mineira e Canto das três raças, entre outras, verifica-se que o uso do passado africano e das referências à África é apropriado buscando a valorização de uma identidade mestiça, contudo, identificada como a ancestralidade negra.

É interessante notarmos que a ancestralidade africana na obra de Clara remete a uma ancestralidade e identidade negra no plural e heterogênea, não criando nenhuma hierarquia entre meio a tal heterogeneidade identitária. Como podemos observar nos fragmentos de letras de música reproduzidas a seguir, há uma seleção das temáticas afro-brasileiras que gira em torno de elementos afro-mineiros e do cristianismo popular, da exaltação a Orixás do candomblé e da visibilidade dada às práticas do jongo e da capoeira, 
respectivamente, observadas nas letras das canções Congada, Afoxé Para Logun, Candongueiro e Jogo de Angola.

Fragmento de Congada (Romildo e Toninho Nascimento)

Benedito santo de Jesus querido/Valha-me Deus que eu tenho sofrido/ Que santo é aquele/ Que vem no andor/É São Benedito/ Enfeitado de flor/É conga, é conga, é congada/ Bate marimba e tambor/Vou pegar minha espada/ Que eu também sou lutador ...

Fragmento de Afoxé Para Logun (Nei Lopes)

Menino caçador/Flecha no mato bravio/ Menino pescador/ Pedra no fundo do rio/ Coroa reluzente/ Todo ouro sobre azul/ Menino onipotente/ Meio Oxóssi, meio Oxum/ Menino caçador/Flecha no mato bravio/ Menino pescador/ Pedra no fundo do rio/Coroa reluzente/ Todo ouro sobre azul/Menino onipotente/ Meio Oxóssi, meio Oxum/ Eh..., quem é que ele é?/ Ah..., onde é que ele está?/ Axé, menino, axé!/ Fara Logun, Fara Logun, Fál Axé, menino, axé!/ Fara Logun, Fara Logun, Fá ...

Fragmento de Candongueiro (Nei Lopes e Wilson Moreira)

Eu vou me imbora, pra Minas Gerais agora./ Eu vou pela estrada a fora, tocando meu candongueiro, oi./ Eu sou de Angola, bisneto de quilombola./ Não tive e não tenho escola, mas tenho meu candongueiro./ No cativeiro, quando estava capiongo, meu avô cantava jongo, pra poder segurar, oi./ A escravaria quando ouvia o candongueiro/ Vinha logo pro terreiro, para saracotear./ Meu candongueiro, bate jongo dia e noite./ Só não bate quando o açoite quer mandar ele bater, oi/ Também não bate, quando seu dinheiro manda, isto aqui não é quitanda pra pagar e receber...

Fragmento de Jogo de Angola (Paulo César Pinheiro e Mauro Duarte)

No tempo em que o negro chegava fechado em gaiola,/ Nasceu no Brasil, Quilombo e Quilombola./ E todo dia, negro fugia juntando a curriola./ De estalo de açoite, de ponta de faca e zunido de bala/ Negro voltava pra Angola, no meio da senzala./ E ao som do tambor primitivo, berimbau, maraca e violal 
Negro gritava: Abre ala! vai ter jogo de Angola/ Perna de brigar, camará; Perna de brigar olê./ Ferro de furar, camará; Ferro de furar olê./ Arma de atirar camará; Arma de atirar olê olê/ Dança Guerreira/ Corpo do negro é de mola na capoeira/ Negro embola e desembola/ E a dança que era uma festa pro dono da terra/ Virou a principal defesa do negro na guerra./ Pelo que se chamou libertação/ E por toda força, coragem e rebeldia/ Louvado será todo dia/ que esse povo cantar e lembrar o jogo de Angolal da escravidão no Brasil ...

As letras das canções citadas podem contribuir de forma significativa para a valorização da heterogeneidade cultural e identitária afro-brasileira, aspecto importante a ser desenvolvido no ensino-aprendizagem da história afro-brasileira e africana. As contribuições podem nos ajudar a compreender as diferentes formas de experienciar as vivências da negritude em diversos tempos e espaços e as práticas culturais desenvolvidas nesses contextos, rompendo com o essencialismo e com a ideia de pureza étnica e/ou racial que algumas vezes circundam as demandas identitárias. As congadas, os afoxés, os jongos, as rodas de capoeira, os terreiros de umbanda e candomblé, os salões de bailes black, funk, soul e rap, as escolas de samba, os maracatus etc., nos remetem à multiplicidade de formas de inserção cultural e identitária negra brasileira em suas mais diversas cores, texturas sonoras e estéticas e geografias.

Os espetáculos musicais protagonizados pela artista são outros indícios da concepção de uma identidade desenvolvida por Clara. O espetáculo Canto das três raças, estreado em 1977, era musicalmente composto pela heterogeneidade de estilos musicais como samba, capoeira, samba-canção, partido-alto, choro, pontos de candomblé e umbanda. Isso tudo se interligava para mostrar a influência das três raças - africana, portuguesa e índia - na MPB (Fernandes, 2007, p.197). Já sobre o espetáculo de 1981 intitulado Clara mestiça, o biógrafo da interprete afirma:

um espetáculo à altura da artista, que lançava mão até de uma coroa de conchas e búzios africanos ... colocada estrategicamente sobre a fronte, para representar a mistura brasileira. Aquela imagem, altiva como uma rainha, repleta de badulaques que remetiam à África, onde tudo começou, jamais sairia do imaginário de cada pessoa que assistia ao show. (Fernandes, 2007, p.234) 
A adoção de uma concepção identitária mestiça por Clara Nunes é um mote significativo para a compreensão da identidade negra no Brasil. Por meio de tal concepção é possível a problematização da ideia de pertencimento identitário, tratando-o como uma construção relacional, cultural e histórica, em contraposição às configurações essencializadas de pertencimento cultural, racial ou étnico. Portanto, as concepções de "raça" e "etnia" são abordadas por um viés não essencializado, e a identidade é entendida como historicizada e experienciada. Dessa forma, os processos da construção de identidades desenvolvem-se com o auxílio de uma parcela substancial de vestígios do passado que são, frequentemente, apropriados politicamente e potencializados como heranças culturais em dado contexto e recorte temporal.

Partindo desse pressuposto, a reflexão acerca da natureza do pertencimento identitário e da cultura negra produzida na diáspora desenvolveu e desenvolve-se, em grande medida, nas conexões e trânsitos culturais, permeados pelas disputas, lutas, interseções e negociações materiais e simbólicas presentes na circularidade de práticas das culturas europeia, indígena e africana no Novo Mundo, gerando uma cultura híbrida, mas que é apropriada, sobre parte dos seus significados, como negra.

\section{À GUiSA DE CONTRIBUiÇÃo}

Longe de esgotar as possibilidades de apropriação didática da obra de Clara Nunes, buscamos neste artigo problematizar alguns de seus aspectos com o objetivo de ampliar os canais relacionados ao ensino-aprendizado de uma temática ainda relativamente nova na formação inicial e continuada dos licenciados em história.

Nesse sentido, reafirmamos que a incorporação pedagógica de aspectos sobre a trajetória artística de intérpretes e/ou compositores da música popular - neste caso, Clara Nunes - pode ser um recurso significativo para a compreensão do "lugar" renovado que a música ocupa como fenômeno sócio-histórico contemporâneo ${ }^{13}$ e da necessidade de incorporarmos esse artefato cultural como linguagem e recurso didático ao ensino de história. Entendemos que uma história a ser ensinada, assim como, de forma mais ampla, uma educação básica e uma formação de professores comprometida com a ampliação da cidadania não devam preterir o acesso e a construção de metodologias voltadas 
para a leitura crítica dos bens socialmente produzidos, a incorporação das sensibilidades estéticas ao contexto escolar e a superação de narrativas no ensino voltadas para a sedimentação de sentimentos nacionais, supostamente universalistas.

Além disso, é fundamental ressaltarmos que as representações que circulam no universo da canção popular produzida no Brasil são campo de amplo diálogo com o mundo social e espaço a ser explorado para proposição de práticas pedagógicas que interroguem a variedade de formas de representar as experiências históricas negras ocorridas no Brasil. Acreditamos que a compreensão sobre como os afro-brasileiros construíram representações sobre seu passado, seu presente e seus anseios, angústias, aspirações e desejos por meio da canção popular - e, também, como esses sujeitos foram representados por intérpretes e compositores de outros pertencimentos étnico-raciais - pode ser um caminho fundamental para o entendimento dessa fatia do passado ainda pouco explorada em contexto escolar.

\section{REFERÊNCIAS}

ALBIN, Ricardo C. Dicionário Houaiss Ilustrado Música Popular Brasileira. Rio de Janeiro: Instituto Antônio Houaiss; Instituto Cultural Cravo Albin; Paracatu, 2006.

ALMEIDA, Juniele R.; ROVAI, Marta G. de O. (Org.) Introdução à História Pública. São Paulo: Letra e Voz, 2011.

AMARAL, Rita; SILVA, Vagner Gonçalves da. Foi conta para todo canto: as religiões afro-brasileiras nas letras do repertório musical popular brasileiro. Afro-Ásia, Salvador, n.34, p.189-235, 2006. Disponível em: http://www.afroasia.ufba.br/edicao. php?codEd=87; Acesso em: 25 maio 2016.

BAKKE, Rachel R. B. Tem orixá no samba: Clara Nunes e a presença do candomblé e da umbanda na música popular brasileira. Religião e Sociedade, Rio de Janeiro, v.27, n.2, p.85-113, 2007. Disponível em: http://www.scielo.br/pdf/rs/v27n2/ v27n2a05.pdf; Acesso em: 20 maio 2016.

CHARTIER, Roger. A história cultural: entre práticas e representações. Rio de Janeiro: Bertrand Brasil, 1990.

FERNANDES, Vagner. Clara Nunes: guerreira da utopia. Rio de Janeiro: Ediouro, 2007. 
HALL, Stuart. Da diáspora: identidades e mediações culturais. Belo Horizonte: Ed. UFMG; Brasília: Unesco, 2006.

. The spectacle of the 'other'. In:

(Org.) Representation: Cultural representation and cultural signifying practices. London: Sage; Open University, 1997b. p.223-290.

The work of representation. In: . (Org.) Representation: Cultural representation and cultural signifying practices. London: Sage; Open University, 1997a. p.13-74.

HERMETO, Miriam. Canção popular brasileira e ensino de História: palavras, sons e tantos sentidos. Belo Horizonte: Autêntica, 2012.

MAUAD, Ana Maria et al. (Org.) História Pública no Brasil: sentidos e itinerários. São Paulo: Letra e Voz, 2016.

NAPOLITANO, Marcos. História e música. Belo Horizonte: Autêntica, 2002.

PARANHOS, Adalberto. A música popular e a dança dos sentidos: distintas faces do mesmo. Artcultura, Uberlândia: Edufu, n.9, p.22-31, jul./dez. 2004.

RICCI, Cláudia S. Pesquisa como ensino. Belo Horizonte: Autêntica, 2002.

SEVERIANO, Jairo; MELlO, Zuza H. de. A canção no tempo. v.2. São Paulo: Ed. 34, 1998.

\section{NOTAS}

${ }^{1}$ A Lei 10.639/03 torna obrigatório o ensino da História e cultura africana e afro-brasileira nas instituições do ensino básico no Brasil. Já a Resolução 1/2004 do CNE cria as Diretrizes Curriculares Nacionais para a Educação das Relações Étnico-Raciais e para o Ensino de História e Cultura Afro-brasileira e Africana. É importante a consideração de que a referida lei foi alterada pela Lei 11.645/2008. Contudo, neste trabalho, utilizaremos nominalmente a Lei 10.639/03 por a considerarmos como um ato de força política e de redefinição simbólica na discussão em natureza etnorracial na educação brasileira.

2 Para CHARTIER (1990, p.17), as representações do mundo social construídas, embora aspirem à universalidade supostamente ancorada em preceitos da racionalidade, são sempre determinadas pelos interesses de grupo que as forjam. As percepções do social não são de forma alguma discursos neutros, ao contrário, produzem estratégias e práticas que tendem a impor determinada autoridade na busca de fundamentar projetos, escolhas e condutas.

${ }^{3}$ As chamadas informações extramusicais são elementos que não estão localizados na estrutura interna da canção, como a melodia, ritmo, harmonia, letra e a interpretação. São informações situadas fora da música propriamente dita, que dão suporte à percepção de uma produção musical. Capas de álbuns (LPs, CDs, fitas cassetes), biografias, texto de crí- 
tica musical e material de divulgação das gravadoras são exemplos de informações extramusicais.

${ }^{4}$ Trata-se de elementos intrínsecos à natureza da linguagem musical que é simultaneamente poética e musical. Tais como os parâmetros verbopoéticos que estão expressos pelos motivos, as categorias simbólicas, as figuras de linguagem, os procedimentos poéticos em torno da letra e os parâmetros musicais de criação (harmonia, melodia, ritmo) e interpretação apresentados pelos arranjos, as vocalizações etc., proporcionando assim uma forma própria de difundir informações.

${ }^{5}$ Texto anônimo presente na contracapa do LP A voz adorável de Clara Nunes, EMI-Odeon, 1966.

${ }^{6}$ Concomitantemente aos discos lançados por Clara entre 1966 e 1969, a intérprete participou de alguns filmes que surfavam na onda da Jovem Guarda. Nessa curta investida cinematográfica, novamente nenhuma referência às africanidades estava presente.

${ }^{7}$ BAKKE analisa a iconografia presente na capa destes álbuns: A voz adorável de Clara Nunes (1966), Alvorecer (1974), Guerreira (1978) e Clara Nunes: a deusa dos orixás (1984).

${ }^{8}$ ALVES, Adelzon. In: Clara Nunes (1971). LP. EMI-Odeon, 1971.

${ }^{9}$ Para uma discussão aprofundada acerca das concepções de representação, ver: HALL, 1997a.

${ }^{10}$ Para CHARTIER (1990, p.17), as lutas de representações têm tanta importância como as lutas econômicas para compreender os mecanismos pelos quais um grupo impõe, ou tenta impor, a sua concepção do mundo social, os valores que são seus, e o seu domínio.

${ }^{11}$ Segundo SEVERIANO e MELLO (1998) trata-se de pontos de religiões de matriz africana adaptados para os parâmetros da indústria fonográfica, com duração aproximada aos padrões radiofônicos, em média 3 minutos.

${ }^{12}$ Ver: ALMEIDA; ROVAI (2011); MAUAD et al. (2016).

${ }^{13}$ Como afirma NAPOLITANO (2002, p.7), a canção popular é um "lugar privilegiado na história sociocultural, lugar de mediações, fusões, encontros de diversas etnias, classes e regiões que formam o nosso grande mosaico nacional. Além disso, a música tem sido, ao menos em boa parte do século $\mathrm{XX}$, a tradutora dos nossos dilemas nacionais e veículo de nossas utopias sociais".

Artigo recebido em 12 de outubro de 2016. Aprovado em 28 de novembro de 2016. 